\title{
Nenad Kecmanović*
}

\author{
Оригинални научни рад \\ UDK 341.211:323(497. 6 Republika Srpska)
}

\section{SRPSKA U BOSNI I HERCEGOVINI I IZVAN NJE * SRPSKA IN BH AND OUT OF IT}

\begin{abstract}
The author analyses the attitude of the RS political elite towards the resolution of the so-called Bosnian crisis, noting several coexisting approaches. $\mathrm{Na}$ tional independence and secession, unification with the motherland, a confederate status, return of abducted jurisdictions, defence of the Dayton status quo and so on - these are just some of the possible options. The author exposes their political implications in a comparative manner, discussing their advantages and disadvantages. In the conclusion he suggests that some of these are primarily tactical, while some are strategic, and that the practical and political discourse should not be confused with the theoretic and political one. As an example of the latter, which does not have to take into account the political correctness and international opportunism, he mentions the attitude of the RS towards its historical founders and their public cover-up.
\end{abstract}

Key words: future of $R S$ and $B H$, Dayton and Washington agreements, Serbs, Bosniaks, Croats,autonomy, secession, unification, motherlands, confederacy, Hague Tribunal

Rezime. Autor analizira odnos političke elite $R S$ prema razrješenju tzv. bosanske krize i uočava nekoliko pristupa koji su istovremeno u opticaju. Otcjepljenje $i$ državno osamostaljenje, ujedinjenje sa maticom, konfederalni status, vraćanje otetih nadležnosti, odbrana dejtonskog status quo-a itd. - to su samo neke od opcija koje su u igri. Autor komprativno izlaže njihove političke implikacije,te razmatra mane i prednosti. U zaključku ukazuje na to da neke imaju prvenstveno taktički a neke više strateški karakter i da praktičnopolitički diskurs ne treba miješati sa teorijskopolitičkim. Kao primjer ovog drugog diskursa, koji ne mora da vodi računa o političkoj korektnosti i međunarodnom oportunitetu, navodi odnos RS prema njenim istorijskim osnivačima te njihovom javnom prećutkivanju.

Ključne riječi: budućnost $R S$ i BiH, Dejtonski i Vašingtonski sporazum, Srbi, Bošnjaci, Hrvati, autonomija, secesija, ujedinjenje, matice, konfederacija, Haški sud

Tokom dvije decenije burne istorije, RS je svoje najbolje godine imala u prvom i u posljednjem petogođu. Izuzmemo li godine uoči rata, tokom rata i prve poratne, kada se političko vođstvo srpskog nacionalnog pokreta uspješno nosilo sa hegemonističkim pritiscima bošnjačko-hrvatskog saveza, a njena vojska nizala pobjede u građanskom ratu, RS je sve do polovine prve decenije ovog vijeka bila u defanzivi. Već sa krajem mandata prvog visokog predstavnika Karla Bilta, koji je u

\footnotetext{
${ }^{\star}$ Redovni profesor Fakulteta političkih nauka Univerziteta u Banjoj Luci.
} 
skladu sa izvornim dejtonskim ovlašćenjima ohrabrivao i pomagao procese poratne normalizacije, OHR je započeo proces sistematskog podrivanja RS.

Vestendorf je nekim konkretnim antidejtonskim potezima samo najavio projekat rušenja manjeg entiteta, koji je tokom mandata Petrića, a pogotovo Ešdauna, uz pomoć bonskih ovlašćenja, bio gotovo priveden kraju. Čitavu deceniju između 1996 i 2006. trajalo je otimanje entitetskih nadležnosti, nametanje zakona, smjenjivanje funkcionera ili ucjenjivanje Haškim tribunalom zbog ratne prošlosti. Kulminaciju je, čini se, predstavljalo ukidanje VRS koja se u vrijeme raspada SFRJ, kada su zakazali svi pokušaji da se budućnost BiH riješi Beogradskom inicijativom ili Lisabonskim sporazumom, pokazala kao posljednji bastion odbrane srpskog naroda. Sjetimo se tog perioda kada se među nacionalnom političkom elitom i u narodu bezmalo oplakivala RS, širio se gorak ukus poraza, beznađa i uzaludnosti svakog otpora.

Svojevrstan preokret je nastao kada su Čavić kao predsjednik, Ivanić kao premijer i Dodik kao lider opozicije jedinstveno i odlučno odbili da se ukine i policija RS. A potom je proces ispravljanja kičme i uspravnog hoda političkog vođstva RS nastavljen krupnim koracima svih posljednjih šest godina. Što je najvažnije, to je povratilo samopouzdanje srpskom narodu, a ovo opet, povratno, generisalo novu energiju i odlučnost lidera. Pri tome, naravno, ne treba zanemariti značaj promjena koje su u međuvremenu nastale u globalnoj konstelaciji snaga u svijetu, a prije svega zamjenu unipolarizma multipolarizmom. ${ }^{1}$ Kao ni vještinu rukovodstva RS da to iskoristi na optimalan način.

Danas se o RS, ni u BiH ni u svijetu, više ne govori kao o zločinačkoj tvorevini, niti o manjem entitetu kao o ekonomski neodrživom, a sve manje i kao o remetilačkom faktoru na putu ka evropskim integracijama. I dok se Srpska potvrdila kao bolji ili bar kompaktniji, funkcionalniji i stabilniji dio međunarodno priznate države bez unutrašnjeg legitimiteta, na dnevni red je stiglo ne samo raspadanje $\mathrm{BiH}$ nego i Federacije. O tome su saglasni i unutrašnji akteri i spoljnji faktori, a jedina razlika je u tome kako ko taj objektivni proces subjektivno vrednuje. Neki ga smatraju posljedicom greške koja je ugrađena u Dejtonski ili samo Vašingtonski sporazum, koju bi trebalo naknadno korigovati. Neki drugi pak vjeruju da je problem u tome što je OHR implementaciju ustavnog dijela mirovnog sporazuma pogrešno vodio na terenu, bilo zbog viška ili zbog manjka nasilnih intervencija. A ima onih koji cijene da se naprosto radi o prirodnom društvenom dovršetku procesa teritorijalno-etničkog zaokruživanja novih država na Balkanu, koji je započeo raspadom SFRJ i sada se neminovno nastavlja na Kosovu, u Makedoniji i BiH. ${ }^{2}$

\footnotetext{
1 Aktivan stav kineskog u ruskog ambasadora u SB UN povodom Inckove inicijative da se prema predsjedniku RS zbog najave referenduma primjene bonska ovlaštenja, ukazuje da se status RS više neće rješavati isključivo na relaciji Vašington - Brisel. A ulazak ruskih kompanija u energetski sistem RS (Brod, Modriča, krak Južnog toka), te višekratni susreti Putin - Dodik, da Moskva daje podršku aktuelnom rukovodstvu u Banjaluci.

2 Vidi: Nenad Kecmanović, Dometi demokratije - od Istočne Evrope do Zapadnog Balkana, Čigoja, Beograd, 2005. str. 231-255.
} 
Tokom dvogodišnjeg perioda osjeke interesa SAD i EU za BiH, što zbog problema u evrozoni i previranja na Bliskom istoku, što zbog deficita novih ideja šta sa Bosnom, Rusija, Kina, pa na specifičan način i Izrael, podržale su Srpsku, Njemačka je zaštitila Hercegbosance, a Turska se napadno angažovala u prilog muslimanskog dijela Federacije. Sada vodeće države Zapada najavljuju nove inicijative prema BiH. Još uvijek samo neformalno, Amerikanci najavljuju rekonstrukciju FBiH, a Britanci, takođe neformalno, novi Berlinski kongres za $\mathrm{BiH} .^{3}$

Kakva je strategija RS za predstojeći susret sa takvim inicijativama? Ili šta bi Srpska mogla da stavi na sto kao svoju projekciju za narednih, ako ne čitavih 20, a ono pet ili 10 godina? U izjavama vodećih političara može se prepoznati barem pet različitih pristupa, koje bih sažeto imenovao kao:

- odbrana status quo-a, - povratak na izvorni Dejton, - mirni razlaz i osamostaljenje, - pripajanje matici i - konfederacija.

\section{Odbrana status quo-a}

Odbrana status quo-a, odnosno aktuelne pozicije RS u BiH ima svoj puni smisao i opravdanje već samim tim što je u okviru datih okvira, uz sve limite, manji entitet postao bolji entitet. Uprkos dvadesetogodišnjim osporavanjima i pritiscima, odbranjeni su suverenitet RS i identitet srpskog naroda. Izjalovila su se neskrivena očekivanja Sarajeva, pa i nekih međunarodnih krugova da će se RS sama od sebe vremenom urušuti na bazi svojih strukturalnih manjkavosti, te da će stanovnici navodno autoritarne i zaostale Srpske poželjeti da se pripoje tobože demokratskoj i prosperitetnoj Federaciji, baš kao što su istočni Nijemci pohrlili preko granice ka Zapadnoj Njemačkoj. Iako RS danas i teritorijalno i funkcionalno predstavlja manje od onoga što je dobila Dejtonskim sporazumom, iako su joj otete mnogobrojne nadležnosti i nametnuti ne manje brojni zakoni, to nije bila prepreka da ne samo opstane nego i da napreduje. Utoliko odbrana aktuelnog statusa može da se tretira kao sasvim realan i dovoljan cilj preko koga i nije politički mudro ići jer predstavlja suvišan rizik od spoljne i unutrašnje reakcije.

\section{Vraćanje oduzetih nadležnosti}

Prema drugom pristupu, RS ima ne samo interes nego i pravo da zahtijeva da joj se vrate oduzete nadležnosti i izvrši revizija nametnutih zakona, čak i u onim slučajevima gdje je sve naizgled izvedeno na legalan i legitiman način. Skupštinska tijela u Banjaluci su tobože demokratski prihvatala zapravo diktat visokih predstavnika i nije teško naknadno rekonstruisati i dokazati da je to učinjeno pod prijetnjom, prinudom i ucjenom. Štaviše, duge mandate Volfganga Petriča, koji je u aerodromskom VIP salonu pred odlazak iz BiH diktirao svoje posljednje antidejtonske mjere, i Pedija Ešdauna, koga su i njegovi zemljaci nazivali posljednjim diktatorom

3 Više medija u regionu najavilo je tokom oktobra i novenbra o.g. da se za proljeće 2013. priprema
rekonstrukciju FBiH „,kako bi se Hrvati osjećali ravnopravniji, Bošnjaci zadržali dominaciju“. A ser
Ajvor Roberts pominje još uvijek neformalnu inicijativu da se pripremi novi „Berlinski kongres“ i
dogovor o novim mapama na Balkanu kako bi se izašlo iz ćorsokaka. (intervju Politici od 11. 07. 2012) 
Ненад Кецмановић: Српска у Босни и Херцеговини и изван ње

u Evropi, međunarodna zajednica je vrednovala kao najproduktivniji i najkreativniji period djelovanja OHR-a. Aktuelna vlast u RS je protiv ovog posljednjeg pokrenula tužbu pred britanskim pravosuđem. Ali i bez obzira na neizvjestan ishod sudskog procesa, povratak na izvorni Dejton može da bude legitiman politički cilj na eventualnoj međunarodnoj konferenciji na kojoj će se svoditi računi u regionu, kao i u lokalnim pregovorima sa domaćim partnerima.

\section{Državno osamostaljenje}

Mirni razlaz, odnosno osamostaljenje RS, u noviji vrijeme se pominje kao najlogičniji ishod hronične krize međunacionalnih odnosa, sada ne samo u BiH, nego i u Federaciji. Jedini ishod dvogodišnje "platformaške" avanture sveo se na probuđeni hrvatski otpor prema zajedničkom entitetu i rasulo u bošnjačkim političkim redovima. Došlo je vrijeme da Republika Srpska tretira Federaciju kao balast na putu za Brisel, a odande stižu poruke da EU odustaje od višegodišnjih prijetnji ustavnim reformama i funkcionalnom centralizacijom, te samo traži da partneri u $\mathrm{BiH}$ počnu da sarađuju u nekoliko ključnih pitanja. Neizvjesno je da li će i kada SAD, pod pritiskom disolucionih procesa na terenu, odustati od stava da je $\mathrm{BiH}$ geopolitička neminovnost i da se ne mogu mijenjati postojeće granice na Balkanu. ${ }^{4}$ Odnosno da li će nakon predaha nastaviti sa pritiscima ili će, konačno, napraviti neophodan korak natrag iz ćorsokaka $u$ kojem su se zaglavile $i$ krenuti nekim drugim putem u raspetljavanju bosanskog čvora, koji podrazumijeva i mirni razlaz. Srpska bi u međuvremenu morala napraviti kalkulaciju svoje ne samo ekonomske samoodrživosti.

\section{Ujedinjenje sa "maticom"}

Ujedinjenje Srpske sa Srbijom više se pominje kao želja naroda sa lijeve obale Drine nego kao dugoročan projekat političkog rukovodstva. A izlazak BiH iz skraćene Jugoslavije i zajednice sa Srbijom i Crnom Gorom početkom 90-ih prihvaćen je kao cijena koju su "prekodrinski Srbi" platili da bi dobili Republiku Srpsku. Istovremeno, i neki zapadni naučnici smatraju da se "balkanska odiseja" može srećno završiti jedino prekompozicijom državnih granica u skladu sa teritorijalno-etničkim i da je samo neizvjesno kada će se to dogoditi. ${ }^{5}$ 5) Navodno, de fakto nezavisno Kosovo, kao i zapadni dio Makedonije i južni dio Crne Gore će se, prije ili kasnije, sasvim prirodno pripojiti državi Albaniji, a to isto važi i za Srpsku, pa i Herceg-Bosnu, koja je već na vidiku, u odnosu na susjedne "matice". Evropske integracije zapadnog Balkana tu operaciju neće skinuti sa dnevnog reda, nego je

\footnotetext{
4 Više medija u regionu najavilo je tokom oktobra i novenbra o.g. da se za proljeće 2013. priprema rekonstrukciju FBiH „,kako bi se Hrvati osjećali ravnopravniji, Bošnjaci zadržali dominaciju“. A ser Ajvor Roberts pominje još uvijek neformalnu inicijativu da se pripremi novi „Berlinski kongres“ i dogovor o novim mapama na Balkanu kako bi se izašlo iz ćorsokaka. (intervju Politici od 11. 07. 2012)

5 Američki istoričar Gal Stouks smatra da nije ključno pitanje da li će se proces stvaranja kompaktnih etničkih država na Balkanu ostvariti nego samo na koji način će se dogoditi. „Naša politika multikulturizma i toleranciije u Bosni ne može da funkcioniše i zato treba odrediti nove državne granice u skladu sa etničkim“ (u: „Jugoslavija i njeni povjesničari“, ur. Naimark, Norman, Case, Holly, izd. Srednja Evropa, Zagreb 2005, str. 165-167).
} 
samo učiniti bezbolnom. Naravno, ni to se neće dogoditi samo od sebe i za pojedina ujedinjenja biće neophodna obostrana nastojanja i pogodan istorijski splet okolnosti. Predsjednik RS je u intervjuu "Politici" u junu ove godine prvi put pomenuo da su Srbi propustili povoljan trenutak kada su kosovki Albanci proglasili nezavisnost jer Srbija zbog odbrane teritorijalnog integriteta nije na to bila spremna.

\section{Asimetrična konfederacija}

Rekonstrukcija današnje BiH kao konfederacije ili unije za sada izgleda kao najbliža i najizglednija promjena koja bi Srpskoj, bez većih potresa, obezbijedila puni državni kapacitet u oviru zajednice sa hrvatskom republikom Herceg-Bosnom i Bošnjačkom republikom. RS je praktično već vrlo blizu takvog statusa, a rasplet bošnjačko-hrvatskih nesuglasica očigledno ide u pravcu formiranja zajednice kantona sa etničkim većinama ili dva nacinalna poluentiteta. Koncentrisani u tri teritorijalno-etnički relativno kompaktne i dovoljno autonomne cjeline, Srbi, Bošnjaci i Hrvati bi se osjećali bezbjedni i, rastrećeni uzajamnih ratnih strahova i nepovjerenja, bili spremniji na saradnju. Takva BiH, komotna za sva tri naroda, uz slobodan protok ljudi, ideja, kapitala, informacija, robe i usluga, mogla bi da bude i demokratski verifikovana. Dejtonski ustav jesu potpisali predstavnici sve tri nacionalne strane, ali uspostavljanje $\mathrm{BiH}$ na novim principima nikada nije stavljeno na referendum nijednog od tri naroda. BiH kao asimetrična konfederacija ili kao konfederacija $\mathrm{RS}$ i FBiH mogla bi da obezbijedi autentičan unutrašnji legitimitet državnoj zajednici tri nacionalne republike i obezbjede sadržaj međunarodnom legitimitetu, koji je još prije 20 godina Srbima nesrećno nametnut prijemom BiH u UN. Prednost ovog modela preuređenja BiH, gledano iz srpskog ugla sastoji se u tome što glavninu preostalog posla RS može da prepusti hrvatskim i bošnjačkim komšijama u većem entitetu. ${ }^{6}$

\section{Strategija i taktika, nauka i politika}

Neki od ovih pristupa su komplementarni ili kumulativni, ali ne bi trebalo da zbuni ni to što se neki od njih međusobno isključuju. Kada je riječ o praktičnopolitičkom diskursu, treba računati da se neke ideje ponekad ističu samo iz taktičkih razloga, kao što se neke druge iz istih razloga prećutkuju, ili samo implicitno pominju jer u datom istorijskom kontekstu nisu oportune. Uzmimo kao primjer ponašanje republika Slovenije i Hrvatske prilikom raspada SFRJ. U fazi početka krize nijedna od njih nije otvoreno zastupala osamostaljenje, nego samo demokratsku prekompoziciju zajedničke države. Milošević je insistirao na čvrstoj federaciji, što je bilo u skladu sa ustavom, a Kučan i Tuđman na legalizaciji konfederacije koja je bila uveliko uzela maha u političkoj praksi. Za posmatrače sa strane izgledalo je da ne samo onaj prvi nego ni ovi drugi ne dovode u pitanje opstanak jugoslavenske države. Kasnije su, međutim, i Kučan i Tuđman potvrdili da im je konfederacija trebalo da posluži samo kao prelazna etapa ka potpunom osamostaljenju. Tako je i Alija Izet-

\footnotetext{
6 Tokom aktuelnih hrvatsko-bošnjačkih tenzija u FBiH, koje su isprovocirali „, platformaši“, aktuelna vlast u RS je zauzela stranu, braneći hrvatsku ravnopravnost od bošnjačke dominacije, ne samo u izbornom sistemu. Neki predstavnici opozicije (Mladen Ivanić, npr.), smatraju da ovo miješanje u probleme u drugom entitetu nosi rizik uvlačenja RS i u njihovo rješavanje,
} 
Ненад Кецмановић: Српска у Босни и Херцеговини и изван ње

begović dao mandat Adilu Zulfikarpašiću da pripremi tzv. beogradski ili istorijski sporazum sa srpskom stranom, a onda uoči samog potpisivanja otkazao podršku. Lisabonski sporazum je čak i sam parafirao da bi po povratku u Sarajevo povukao potpis. Kasnije je to objasnio kao zavaravanje protivnika odnosno kupovinu vremena do očekivanog međunarodnog priznanja BiH. Mnogi i Dodikove višekratne najave referenduma tumače kao taktičke prijetnje na adresu Vašingtona, Brisela i Sarajeva. Odustajanje u posljednji čas obično dolazi nakon neke koncesije druge strane, ili ima efekat kooperativnosti za koju slijedi odgovarajuće priznanje. No, dok praktična politika mora da taktizira i lavira, zaobilazi i kamuflira, simulira i blefira, politička teorija, naprotiv, uživa slobodu, ali i obavezu, da se svakom od navedenih i nenavedenih opcija bez zazora direktno i otvoreno kritički pozabavi i ponudi stratešku bazu za dnevnopolitičke odluke.

\section{Izostalo priznanje osnivačima}

U red takvih tema, ne samo povodom velikog jubileja RS, svakako spada i savremeni tretman njenih osnivača. Neprirodno je da se jubilarna godina približava kraju a da se ne pominju ta imena. Naravno, Srpsku nisu stvarali ni političari ni generali, nego narod, kako u ratu, tako i u miru. Ali, kao što uvijek i svugdje biva, predvodili su ga njegovi civilni rukovodioci i vojni komandanti. Jeste da se dvojici pojedinačno najistaknutijih upravo sudi na Međunarodnom sudu za ratne zločine i da RS sarađuje sa tim sudom, ali sve do pravosnažne presude postoji presumcija nevinosti. A od dvoje potpredsjednika RS protiv jednog nije ni podignuta optzužnica, a drugi je odslužio kaznu. Čak i da imamo najveće povjerenje u Haški tribunal i u objektivnost presuda, istorijska uloga prvog predsjednika RS i komandanta VRS ne može se redukovati na tzv. komandnu odgovornost ili odgovornost zbog nečinjenja u građanskom ratu. Uostalom, pogledajmo druge primjere iz ratova na zgarištu Jugoslavije. Snimci razgovora u kabinetu hrvatskog predsjednka nedvosmisleno pokazuju da je Tuđman naredbodavno odgovoran za etničko čišćenje i zločine tokom "Oluje", a on je bio i taj koji je na salveti dijelio BiH napola. Pa ipak, u Hrvatskoj i Herceg-Bosni ga i dalje slave kao osnivača hrvatske države. ${ }^{7} \mathrm{U}$ svakoj biografiji, pa i u biografijama vođa sprskog nacionalnog pokreta u BiH, mora se pažljivo razlučiti šta je bilo dobro a šta nije. Ne samo zbog nacionalnog duga prema tim ličnostima $i$ istorijske istine radi nego i radi RS i naroda koji ovdje živi. Sve dok to ne učinimo, slušaćemo iz komšiluka da je Srpska zločinačka tvorevina. Međunarodna zajednica nije samo osnovala Haški sud da kazni ratne zločine nego je i napisala Dejtonski ustav, koji je verifikovao ishod građanskog rata iz koga je rođena Republika Srpska.

\footnotetext{
7 Oslobađajuće presude u Hagu za komandante operacije „Oluja“, generale Gotovinu i Markača i nisu imale toliko za cilj da isključe pokojnog Tuđmana iz „udruženog zločinačkog poduhvata“ koliko da amnestiraju američke obavještajce, instruktore i logističare, koji su u koordinaciji ambasadora Galbrajta bili involvirani u „vojni poduhvat“. Oslobađajuća presuda za Haradinaja, koji je vlastoručno napisao i objavio da je ubijao srpske civile i nelojalne sunarodnike, pa treba očekivati i naknadno javno priznanje kako je dvadeset potencijalnih svjedoka pojeo mrak, predstavlja još jedan dokaz da su učesnici u globalnim projektima supersile zaštićeni od prava i pravde. Dobra strana ova dva haška skandala jeste u tome što su konačno probudili međunarodnu stručnu javnost i postidjeli prosvijećene srpske nacionalne mazohiste i autošoviniste.
}

Banja Luka, 17.9.2012. 